University of Nebraska - Lincoln

DigitalCommons@University of Nebraska - Lincoln

Faculty Papers and Publications in Animal

Science

Animal Science Department

December 1976

\title{
REPRODUCTIVE PERFORMANCE OF SWINE BRED TO PRODUCE PUREBRED AND TWO-BREED CROSS LITTERS
}

L. D. Young

Oklahoma Agricultural Experiment Station, Stillwater

R. K. Johnson

University of Nebraska-Lincoln, rjohnson5@unl.edu

I. T. Omtvedt

U.S. Department of Agriculture, El Reno, iomtvedt1@unl.edu

Follow this and additional works at: https://digitalcommons.unl.edu/animalscifacpub

Part of the Animal Sciences Commons

Young, L. D.; Johnson, R. K.; and Omtvedt, I. T., "REPRODUCTIVE PERFORMANCE OF SWINE BRED TO PRODUCE PUREBRED AND TWO-BREED CROSS LITTERS" (1976). Faculty Papers and Publications in Animal Science. 78.

https://digitalcommons.unl.edu/animalscifacpub/78

This Article is brought to you for free and open access by the Animal Science Department at DigitalCommons@University of Nebraska - Lincoln. It has been accepted for inclusion in Faculty Papers and Publications in Animal Science by an authorized administrator of DigitalCommons@University of Nebraska - Lincoln. 


\title{
REPRODUCTIVE PERFORMANCE OF SWINE BRED TO PRODUCE PUREBRED AND TWO-BREED CROSS LITTERS
}

\author{
L. D. Young ${ }^{2}$, R. K. Johnson ${ }^{2}$ and I. T. Omtvedt ${ }^{3}$ \\ Oklaboma Agricultural Experiment Station, Stillwater 74074 and \\ U.S. Department of Agriculture, El Reno 73036
}

\section{SUMMARY}

These data included the records of 818 purebred gilts and sows of Duroc, Hampshire and Yorkshire breeding mated to produce all purebreds and all possible two-way crosses. A total of 212 gilts were slaughtered 30-day postbreeding (72 purebred matings and 140 crossbred matings) to evaluate ovulation rate, number of live embryos, average embryo length and embryo survival rate. A total of 450 litters (161 purebred and 289 crossbred) were farrowed to evaluate litter size, litter weight and average pig weight at 0,21 and 42 days postfarrowing. Litters were farrowed in the spring and fall of 1971 and 1973 and the summer of 1972.

of the 818 females selected for breeding, $16.4 \%$ failed to exhibit estrus or to be pregnant at slaughter or farrowing. Failure rates were similar for sows and gilts with Yorkshires having the most and Hampshires the least. Duroc and Yorkshire females ovulated more eggs and had more embryos 30 days postbreeding than did Hampshire females $(P<.05)$. Yorkshires were the most productive of the straightbreds in terms of litter size and weight. Breed of dam and breed of sire effects were evident for many traits evaluated.

Heterosis estimates were not significant for embryo data but were large and significant for litter size and weight at 42 days postfarrowing due to the $7.78 \%$ higher survival rate of the

\footnotetext{
IJournal Article 2999 of the Agricultural Experiment Station, Oklahoma State University, Stillwater. Research conducted by the Department of Animal Science and Industry (Project 1444) in cooperation with the U.S.D.A., Agricultural Research Service, Southern Region.

${ }^{2}$ Department of Animal Sciences and Industry, Oklahoma State University, Stillwater $\mathbf{7 4 0 7 4 .}$

${ }^{3}$ Department of Animal Science, University of Nebraska, Lincoln 68503.
}

crossbred pigs. Duroc and Hampshire dams expressed significant response to crossbreeding regardless of the breed of sire used for crossbred litter production, but Yorkshires did not. However, Yorkshire dams had larger and heavier litters when mated to Duroc boars compared to Yorkshire boars.

(Key Words: Swine Crossbreeding, Reproduction.)

\section{INTRODUCTION}

Most measurements of sow productivity are estimated to be lowly heritable and are theoretically expected to exhibit heterosis under a crossbreeding system. Only a few crossbreeding experiments utilizing non-inbred parents have been reported and a majority of these were conducted prior to the arrival of the "modern" type pig. Several experiments lacked proper controls and sufficient numbers to allow for adequate interpretation. Because of the absence of crossbreeding information on modern swine breeds raised under confinement conditions, data on the performance of purebreds and their crosses is needed in order to develop breeding programs that will maximize performance.

Johnson and Omtvedt (1973) reported the results of three replications of an experiment which was designed to evaluate the reproductive performance of purebred Duroc, Hampshire and Yorkshire females when producing purebred and two-breed cross litters. Two additional replications have been finished to complete this phase of the project and the data from all five replications are presented in this paper. The addition of two seasons of data increased the number of observations and consequently increased the precision of the estimates. In addition, these analyses include specific comparisons, not presented in the first paper, which provide information which is necessary for the development of sound breeding programs. 


\section{MATERIALS AND METHODS}

The data for this study came from five replications of the first phase of a two phase swine crossbreeding project being conducted at the Fort Reno Experiment Station. Purebred Durocs, Hampshires and Yorkshires were mated to produce purebred and all possible two-breed cross litters. The basic design of this phase of the project has previously been described by Johnson and Omtvedt (1973). A random sample of gilts were slaughtered 30 days postbreeding to evaluate ovulation rate, number of live embryos, average embryo length and the percent of eggs ovulated represented by live embryos (embryo survival). The remaining females were allowed to farrow to evaluate litter size, litter weight and average pig weight per litter at 0,21 or 42 days postfarrowing and the percent of pigs born which were alive at 42 days postfarrowing (pig survival). Neither average embryo length per litter nor average pig weight per litter at 0,21 or 42 days postfarrowing were adjusted for litter size.

This paper includes the records of 603 gilts and 215 sows that were available for breeding. Ninety-seven gilts and 37 sows were considered to have reproductive failures when they failed to exhibit estrus, returned to estrus after several services, were open at slaughter or failed to carry a litter to term. In addition, 15 slaughter records and 22 farrowing records were discarded due to the loss of part of the reproductive tract at slaughter or due to serious illness or injury of the female prior to slaughter or farrowing. The distribution of the records utilized in the analyses of the various traits is presented by mating type in table 1 .

The formation and the maintenance of the seedstock herds which provided the purebred boars and gilts utilized in this project have previously been described by Johnson et al. (1973). Herd management and method of data collection were described in detail by Johnson and Omtvedt (1973). The records utilized in this study were from sows and gilts that were bred to farrow in the spring and fall of 1971 and 1973 and the summer of 1972. Due to management difficulties described by Johnson and Omtvedt (1973) and in order to increase numbers, second litter sows were farrowed in three of the five seasons. Only gilts were bred to farrow in the spring of 1971 and 1973. For the fall 1971 and 1973 farrowing seasons, each boar was mated to at least two gilts and one sow of each breed, and one gilt and one sow from each boar mating type were allowed to farrow and all remaining gilts were slaughtered 30 days postbreeding. Only second litter sows were farrowed in the summer of 1972 and second litter sows were never slaughtered. All sow records were adjusted to a gilt equivalent based on the observed average difference between sows and gilts in the fall 1971 and fall 1973 farrowing seasons. The average difference between gilts and sows was subtracted from the sow records for litter size and average pig weight per litter at 0,21 and 42 days postfar-

TABLE 1. NUMBER OF RECORDS FOR EMBRYO TRAITS AND OVULATION RATE, NUMBER OF LITTER RECORDS FOR BIRTH TRAITS AND RATE OF SURVIVAL AND NUMBER OF LITTER RECORDS FOR 21 - AND 42-DAY TRAITS FOR EACH MATING TYPE

\begin{tabular}{llll}
\hline & $\begin{array}{l}\text { Embryo traits } \\
\text { and ovulation } \\
\text { rate records }\end{array}$ & $\begin{array}{l}\text { Birth traits } \\
\text { and rate of } \\
\text { survival records }\end{array}$ & $\begin{array}{l}\text { 21-Day and } \\
\text { 42-Day trait } \\
\text { records }\end{array}$ \\
\hline D X D & 25 & 55 & 52 \\
HXH & 28 & 56 & 50 \\
Y XY & 19 & 50 & 49 \\
D X H & 27 & 52 & 50 \\
D X & 18 & 46 & 46 \\
HXD & 22 & 45 & 44 \\
HXY & 15 & 40 & 40 \\
YX D & 29 & 50 & 50 \\
YXH & 29 & 56 & 56 \\
Total & 212 & 450 & 437 \\
\hline
\end{tabular}

\footnotetext{
${ }^{\mathrm{a}} \mathrm{D}=$ Duroc, $\mathrm{H}=$ Hampshire, $\mathrm{Y}=$ Yorkshire. First letter indicates breed of sire and second letter indicates breed of dam.
} 
rowing. Total litter weight at each age and pig survival rate were calculated using the adjusted data. The differences between sows and gilts were considerably different for the three dam breeds suggesting that different adjustments be used for each dam breed. The adjustments for litter size and average pig weight at the various ages are presented by dam breed in table 2 .

At birth, the adjustment for litter size was 1.66 pigs for Hampshire gilts and -.33 pigs for Yorkshire gilts. These were significantly different. In all breeds, litters from gilts had approximately one pig less than litters from sows at $\mathbf{2 1}$ and 42 days postfarrowing. At 0 and 21 days postfarrowing the adjustment factor for average pig weight was significantly larger for Yorkshires than Durocs. The adjustment factors for these breeds were not significantly different for 42-day pig weight even though they differed by about 1.0 kilogram. The adjustment factor for average pig weight for Hampshires fell between those of Durocs and Yorkshires at all ages.

All traits were analyzed on a within season basis and pooled over seasons because it was considered necessary to include the effect of service sire in the model as a random effect. Since different sires were used each season, sires needed to be nested within season-breed of sire subclasses if season was to be included in the model. Available computer programs could not do this when sires were considered random. All data were analyzed by the least squares procedures for disproportionate subclasses described by Harvey (1960) and supplemented by mixed model procedures described by Harvey (1972). All traits from birth to weaning and number of embryos per litter were analyzed by fitting the following model within season:
$\mathrm{Y}_{\mathrm{ijkm}}=\mu+\mathrm{B}_{\mathrm{i}}+\mathrm{s}_{\mathrm{j}(\mathrm{i})}+\mathrm{D}_{\mathrm{k}}+\mathrm{BD}_{\mathrm{ik}}+\mathrm{e}_{\mathrm{ijkm}}$ where $Y_{i j k m}=$ the observed value of the dependent variable for the $\mathrm{m}^{\text {th }}$ litter in the ijk $k^{\text {th }}$ subclass, $\mu=$ fitted mean, $B_{i}=$ effect of the $i^{\text {th }}$ sire breed, $s_{j(i)}=$ effect of $j^{\text {th }}$ service sire in the $i^{\text {th }}$ sire breed, $D_{k}=$ effect of the $k^{\text {th }}$ dam breed, $B D_{i k}=$ interaction of $i^{\text {th }}$ sire breed and $\mathbf{k}^{\text {th }}$ dam breed and $e_{i j k m}=$ random element. All effects except $s_{j(i)}$ and $e_{i j k m}$ were considered fixed effects and $s_{j}(i)$ and $e_{i j k m}$ were considered random effects with zero mean and variances $\sigma_{\mathrm{s}}^{2}$ and $\sigma^{2}$, respectively. For the trait average embryo length, the linear and quadratic regression of embryo length on days pregnant were added to the model.

The model used to analyze number of corpora lutea per gilt was: $\mathbf{Y}_{\mathbf{i j k m}}=\mu+\mathbf{B}_{\mathbf{i}}+\mathbf{s}_{\mathbf{j}(\mathbf{i})}$ $+d_{k(i j)}+e_{m(i j k)}$ where $Y_{i j k m}=$ the observed number of corpora lutea for the $\mathrm{m}^{\text {th }}$ gilt in the ijkth subclass, $\mu=$ fitted mean, $B_{i}=$ effect of the $i^{\text {th }}$ gilt breed, $s_{j(i)}=$ the effect of the $j^{\text {th }}$ sire of gilt in the $\mathrm{ith}^{\text {th }}$ breed of gilt, $\mathrm{d}_{\mathrm{k}(\mathrm{ij})}=$ the effect of the $k^{\text {th }}$ dam mated to the $j^{\text {th }}$ sire within the $\mathrm{i}^{\text {th }}$ gilt breed and $\mathrm{e}_{\mathrm{m}(\mathrm{ijk})}=$ random element. The $\mathbf{B}_{\mathbf{i}}$ effects were considered fixed and $s_{j(i)}, d_{k(i j)}$ and $e_{m(i j k)}$ were considered random effects with zero means and variances $\sigma_{\mathrm{s}}^{2}, \sigma_{\mathrm{d}}^{2}$ and $\sigma^{2}$, respectively.

Specific linear contrasts among least squares means were calculated within season for each trait. The linear contrasts and their standard errors were pooled over seasons, giving equal weight to each season. Linear contrasts were constructed to provide information of interest without regard to orthogonality or linear independence and more linear contrasts were made than there were degrees of freedom. Standard errors of comparisons of breeds of dam and

TABLE 2. MEAN DIFFERENCE BETWEEN SOW AND GILT LITTERS FOR LITTER SIZE AND AVERAGE PIG WEIGHT PER LITTER AT 0, 21 AND 42 DAYS POSTFARROWING BY BREED OF DAM

\begin{tabular}{|c|c|c|c|}
\hline \multirow[b]{2}{*}{ Trait } & \multicolumn{3}{|c|}{ Dam breed } \\
\hline & Duroc & Hampshire & Yorkshire \\
\hline \multicolumn{4}{|c|}{ No. pigs at day: } \\
\hline 0 & $.85 \pm .63$ & $1.66 \pm .60$ & $-.33 \pm .68$ \\
\hline 21 & $1.24 \pm .55$ & $1.00 \pm .52$ & $.90 \pm .59$ \\
\hline 42 & $1.26 \pm .54$ & $1.08 \pm .51$ & $1.17 \pm .58$ \\
\hline \multicolumn{4}{|c|}{ Avg pig wt at day $(\mathrm{kg})$} \\
\hline 0 & $.054 \pm .052$ & $.118 \pm .049$ & $.213 \pm .056$ \\
\hline 21 & $.041 \pm .226$ & $.481 \pm .214$ & $.866 \pm .243$ \\
\hline 42 & $.512 \pm .471$ & $.975 \pm .447$ & $1.633 \pm .507$ \\
\hline
\end{tabular}


heterosis estimates were constructed using residual as the error term while the standard errors for all other comparisons utilized sire within breed of sire as the error term. Breed of sire, breed of dam and their interaction were evaluated by linear contrasts of least squares means. Because sire within breed of sire is nested in season, the sum of squares due to sire within breed of sire pooled over season was used for testing sires as a source of variation.

\section{RESULTS}

\section{Reproductive Efficiency}

The distribution of reproductive success and failure of gilts and sows of each breed is presented in table 3. All gilts were between 210 and 270 days of age at breeding. The breeding season of 56 days was long enough to allow problem breeders at least two and in most cases three complete estrus cycles. No measure of physiological age was taken. A female was considered to have a reproductive failure when she failed to exhibit estrus, failed to conceive after several services, failed to be pregnant at slaughter or failed to carry a litter to term. The chi-square test for differences in probability (Conover, 1971) was used to test the hypothesis that the probability of a reproductive failure was the same for all breeds of dam. The failure rate over all dam breeds and ages was 16.4\%. Yorkshires and Durocs had 24.4 and $17.2 \%$ reproductive failures, respectively, which were significantly greater than the failure rate of $6.9 \%$ for the Hampshire gilts. The reproductive failure rate for sows ranked the breeds in the same order as did gilt failure rates, however, the difference between Durocs and Hampshires was not significant.

Overall, the failure rate for Duroc, Hampshire and Yorkshire females was 16.3, 7.7 and $25.4 \%$, respectively, with all differences being significant. These data indicate that more Yorkshires than Durocs and more Durocs than Hampshires must be retained for breeding if a certain number of litters are to be farrowed.

\section{Early Embryo Development}

Analyses of Variance. The analysis of variance for number of corpora lutea per gilt is presented in table 4. Each source of variation was tested for significance by using the entry immediately below it as the error term. The breed of gilt and the gilt's dam were significant sources of variation but the gilt's sire was not. These results suggest that the maternal environment provided by the gilt's dam prior to weaning had a large effect upon the gilt's subsequent ovulation rate.

The sire and residual mean squares and

TABLE 3. TOTAL NUMBER OF FEMALES SELECTED TO BE MATED AND THE DISTRIBUTION OF REPRODUCTIVE FAILURES AND SUCCESS FOR EACH BREED OF DAM

\begin{tabular}{|c|c|c|c|}
\hline \multirow[b]{2}{*}{ Item } & \multicolumn{3}{|c|}{ Breed of dam } \\
\hline & Duroc & Hampshire & Yorkshire \\
\hline \multicolumn{4}{|l|}{ Gilt data: } \\
\hline No. selected to be mated & 204 & 202 & 197 \\
\hline No. pregnant & 169 & 188 & 149 \\
\hline No. opend & 35 & 14 & 48 \\
\hline Percent failures & $17.2^{\mathrm{a}}$ & $6.9 \mathrm{~b}$ & $24.4^{\mathrm{a}}$ \\
\hline \multicolumn{4}{|l|}{ Sow data: } \\
\hline No. selected to be mated & 72 & 72 & 71 \\
\hline No. pregnant & 62 & 65 & 51 \\
\hline No. opend & 10 & 7 & 20 \\
\hline Percent failures & $13.9^{\mathrm{a}}$ & $9.7^{\mathrm{a}}$ & $28.2^{b}$ \\
\hline \multicolumn{4}{|l|}{ Overall: } \\
\hline No. selected to be mated & 276 & 274 & 268 \\
\hline No. pregnant & 231 & 253 & 200 \\
\hline No. opend & 45 & 21 & 68 \\
\hline Percent failures & $16.3^{a}$ & $7.7 \mathrm{~b}$ & $25.4^{\mathrm{C}}$ \\
\hline
\end{tabular}

\footnotetext{
$a, b, c$ Numbers on a row with different superscripts are significantly different at .05 level.

$\mathrm{d}_{\text {Includes those that never exhibited estrus and those bred but not pregnant. }}$
} 
TABLE 4. MEAN SQUARES AND DEGREES OF FREEDOM FOR POOLED ANALYSIS OF VARIANCE FOR NUMBER OF CORPORA LUTEA FOR GILTS SLAUGHTERED 30-DAYS POSTBREEDING

\begin{tabular}{lrc}
\hline Source & df & $\begin{array}{l}\text { No. of } \\
\text { corpora } \\
\text { lutea/gilt }\end{array}$ \\
\hline Breed of gilt (BOG) & 8 & $19.632^{*}$ \\
Sire within BOG [S(BOG)] & 52 & 8.776 \\
Dam within [S(BOG)] & 82 & $6.781^{*}$ \\
Error & 66 & 4.200 \\
\hline
\end{tabular}

* $\mathrm{P}<.05$.

degrees of freedom for number of live embryos, embryo survival rate and average embryo length per litter are presented in table 5. The effect of service sire was not a significant source of variation for any of these traits. Reddy et al. (1958) found that a boar had no significant effect on prenatal death loss. The simultaneous fitting of the linear and quadratic regressions of average embryo length on number of days pregnant, indicated that embryo length exhibited a significant curvilinear growth pattern over the range of days evaluated in this study $(\bar{x}=$ 29.57, S.D. $=2.60$ ).

The pooled least squares breed group means and linear contrasts among means are presented in table 6 for number of corpora lutea and embryo traits.

Comparisons among Breeds of Dam. This contrast evaluates the average performance of each dam breed when mated to all breeds of sire. Duroc and Yorkshire gilts ovulated significantly more eggs than did Hampshire gilts and the difference between Durocs and Yorkshires was not significant. The embryo survival rates for the three dam breeds were not greatly different; however, embryos carried by Yorkshire females had a $7.1 \%$ higher survival rate than embryos carried by Hampshire females
$(P<10)$. Duroc and Yorkshire gilts had more live embryos than Hampshire gilts $(\mathbf{P}<.01)$. Most of the differences seen in litter size were due to differences in ovulation rate because the embryo survival rates were not greatly different for the three dam breeds. Embryos carried by Yorkshire females were significantly shorter than embryos carried by the other two dam breeds. This is probably not simply a function of the number of embryos because Duroc and Yorkshires averaged about the same number of embryos but Durocs had longer embryos $(\mathbf{P}<.05)$.

Comparisons among Breeds of Sire. This comparison evaluates the average performance of a sire breed when mated to all breeds of dam. Differences between breeds of sire were not large or significant for number of live embryos or percent embryo survival. Hampshire boars sired embryos that were $.79 \pm .36 \mathrm{~mm}$ and $1.02 \pm .34 \mathrm{~mm}$ longer than embryos sired by Duroc and Yorkshire boars, respectively.

Combining the breed of sire and breed of dam comparisons indicates that litter size at 30 days postbreeding is largely a function of ovulation rate rather than embryo survival rate and is therefore largely controlled by the breed of dam. However, average embryo length, which is not strictly regulated by number of embryos, is affected by both breed of dam and breed of sire.

Comparisons among Straightbreds. Straightbred Hampshire litters were smaller and had a lower embryo survival $(\mathrm{P}<.05)$ than either straightbred Duroc or Yorkshire litters. If no differences in fertilization rate are assumed, it appears that Hampshire gilts, which ovulated the fewest eggs of the three dam breeds, had a higher embryonic mortality rate prior to 30 days than Duroc or Yorkshire gilts when all gilts carried straightbred litters. When breeds of dam were averaged over all breeds of sire, the differences in embryo survival rate between Hampshires and the other two breeds were not

TABLE 5. DEGREES OF FREEDOM AND MEAN SQUARES FOR SIRES AND ERROR FOR TRAITS EVALUATED 30-DAYS POSTBREEDING

\begin{tabular}{lllll} 
Item & df & $\begin{array}{l}\text { No. embryo } \\
\text { per litter }\end{array}$ & $\begin{array}{l}\text { Embryo } \\
\text { survival rate }\end{array}$ & $\begin{array}{l}\text { Avg embryo } \\
\text { length }\end{array}$ \\
\hline Sire & 64 & 7.328 & 346.55 & 3.789 \\
Residuala & 112 & 6.746 & 377.54 & 3.760 \\
\hline
\end{tabular}

\footnotetext{
${ }^{\mathrm{a}}$ Residual $\mathrm{df}=104$ for average embryo length.
} 


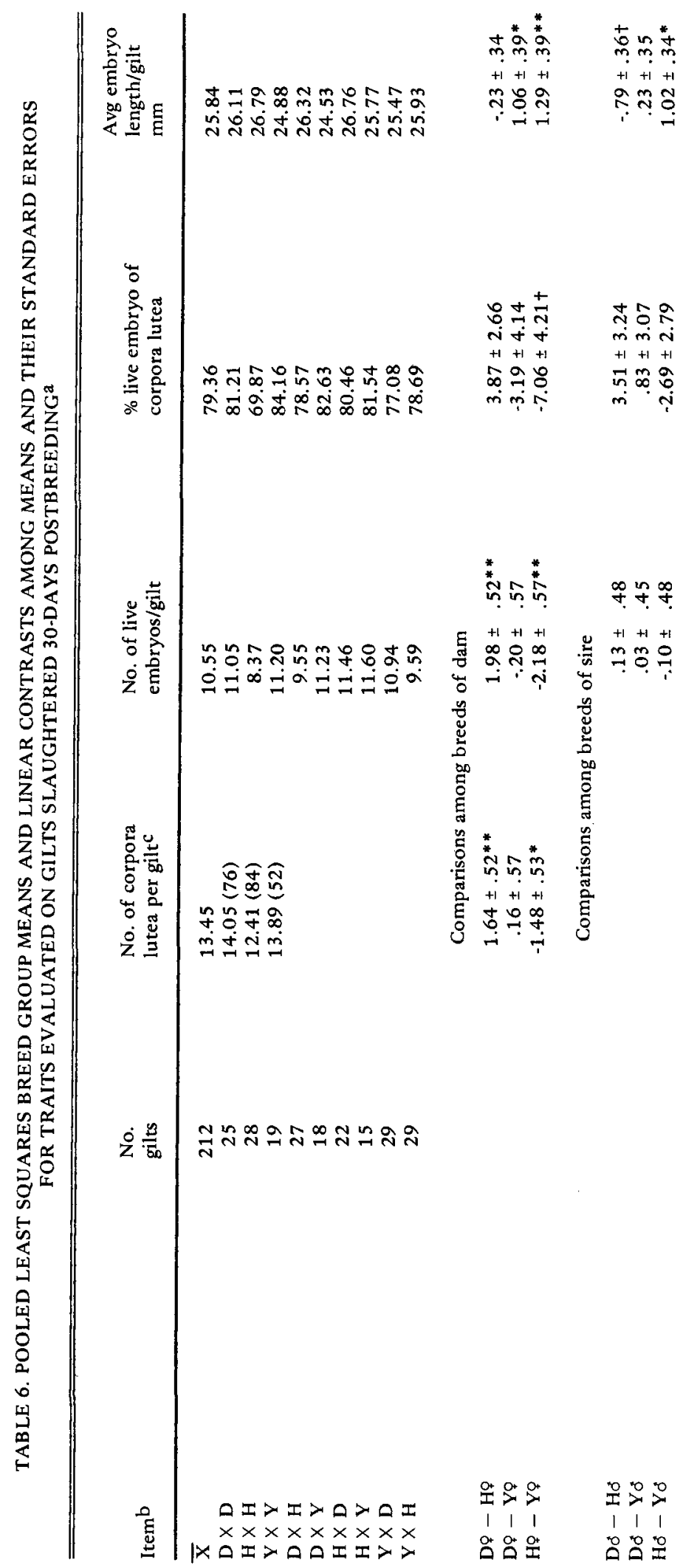


뭉.

s.

s. $\stackrel{+}{+}+\frac{i}{i} \stackrel{m}{m}$

$+1+1+$

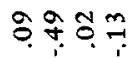

.

No

$+1+1+1$

ma

-

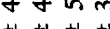

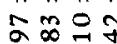

min

Noñ

+2
$+1+\infty$
$+1+1$

+20

i $\infty$

$+1+1$

후유.

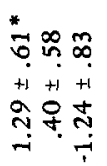

营

is

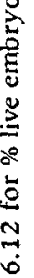

$+1+1$

$\infty \simeq 0$

m?

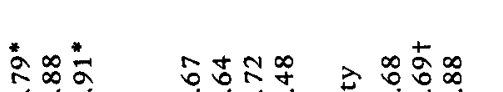

$+1+1+i$

$+1+1+3+1$

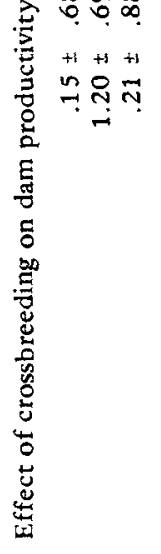

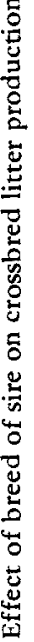

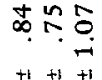

$\infty 000$ 잉

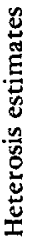

$\underset{x}{x} \times \vec{x}$

$\underset{\substack{0 \\ 0}}{x} \underset{x}{x}$

111

อิำ

$x \times x$

论

$++$

111

어눈

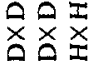

过

즘

젔 
as large as when all gilts carried straightbred litters. The combination of these two sets of comparisons, might imply that the Hampshire breed contains a higher frequency of deleterious recessive genes than the other two breeds, thus causing the excessive embryonic mortality in the straightbred Hampshire litters. Straightbred Yorkshire embryos were shorter than straightbred Duroc $(P<.10)$ or Hampshire $(P<.05)$ embryos.

Heterosis Estimates. Heterosis in this case is a character of the crossbred embryo or pig rather than the dam since all dams were straightbred. None of the heterosis estimates were large in comparison with their standard errors. Crosses involving Hampshires, which had the lowest number of embryos and lowest embryo survival rate, exhibited positive (though nonsignificant) heterosis for number of $\mathrm{em}$ bryos and embryo survival rate. Crosses between Durocs and Yorkshires, which were the highest and about equal for number of embryos and embryo survival rate, showed slightly negative though nonsignificant heterosis for number of embryos and embryo survival rate.

Average Effect of Crossbreeding on Dam Productivity. This contrast measures the average superiority or inferiority of a given breed of dam when producing both types of crossbred pigs as compared to when she produces straightbred pigs. Duroc and Yorkshire females which were significantly better than Hampshires for number of embryos and embryo survival rate, showed no significant average response to crossbreeding for the traits evaluated at 30 days postbreeding. Crossbred litters carried by Hampshire females were $1.20 \pm .69$ pigs larger and had a $8.76 \pm 4.65 \%$ higher survival rate than purebred Hampshire litters.

Effect of Breed of Sire on Crossbred Litter Production. This comparison was made based on the generally accepted result that crossbred pigs exhibit heterosis for livability and some economically important postweaning traits and are therefore generally preferred over the straightbred. It then becomes important to evaluate the differences between breeds of sire used for crossbred litter production in terms of litter size, litter weight and average pig weight. No large or significant differences were seen between breeds of sire within breed of dam for number of embryos and embryo survival rate of crossbred litters. Within Duroc dams, Yorkshire sired embryos were shorter $(P<.05)$ than Hampshire sired embryos $(1.29 \pm .61 \mathrm{~mm})$. Within
Yorkshire females, Duroc sired embryos were $-1.24 \pm .83 \mathrm{~mm}$ shorter than Hampshire sired embryos.

\section{Litter Records at 0, 21 and 42 Days}

Analyses of Variance. The sire and error mean squares and corresponding degrees of freedom for litter traits at 0,21 and 42 days postfarrowing are presented in table 7 . The effect of service sire was a significant source of variation $(P<.10$ to $P<.01)$ for all traits except litter weight at 21 days, average pig weight at birth and pig survival rate. These results are in disagreement with Reddy et al. (1958) who found service sires were not an important source of variation for any litter trait. A total of 81 sires about equally distributed over the three breeds were represented in the analyses.

The least square means, linear contrasts among means and their standard errors for traits evaluated at 0,21 and 42 days are given in tables 8,9 and 10 , respectively.

Comparisons between Breeds of Dam. Large differences were seen between breeds of dam for litter size and, consequently, litter weight at all ages. Yorkshire females had significantly larger litters than Hampshires and Durocs at all ages and by 42 days of age their litters averaged $1.18 \pm .27$ pigs larger and $10.99 \pm 2.87 \mathrm{~kg}$ heavier than litters from Duroc gilts and $1.43 \pm$ .27 pigs larger and $11.83 \pm 2.83 \mathrm{~kg}$ heavier than litters from Hampshire gilts. Litters from Duroc dams were significantly larger and heavier at birth than litters from Hampshire dams; however, by 42 days they had litters of essentially equal size and weight due to the decreased survival rate $(P<.05)$ of pigs from Duroc dams. The average weight at birth for pigs from Yorkshire females was less $(\mathrm{P}<.01)$ than for the other dam breeds. Pigs did not receive creep feed until after 21-day weights were obtained, therefore 21 day pig and litter weights should be a good estimate of maternal or milking ability. At 21 days Yorkshire females had the heaviest litters $(\mathrm{P}<.01)$ but Hampshire females had pigs with the highest average pig weights $(\mathrm{P}<.05)$. By 42 days no significant differences existed between dam breeds for average pig weight, but Yorkshire females had the heaviest litters $(P<.05)$ due to more pigs per litter $(\mathrm{P}<.01)$. Thus, the creep feed consumed between 21 and 42 days of age tended to compensate for milk production and mask breed differences in maternal ability as mea- 
sured by average pig weight but not when measured by total litter weight. This agrees with Ahlschwede and Robison (1971) who reported that the covariance between direct genetic and maternal genetic effects changes with time and results in the equalizing of 8-week body weight.

Comparisons between Breeds of Sire. Breed of sire effects were quite evident for litter size, litter weight and pig survival rate and differences for litter size and litter weight became larger as age increased. Yorkshire boars sired litters that were heavier at all ages $(P \leqslant 10$ to $P \leqslant .01)$ than litters sired by either Hampshires or Durocs. Yorkshire sired litters also contained more pigs at all ages than litters sired by the other two breeds and their advantage became greater as the pigs grew older due to the significantly greater survival rate of the Yorkshire sired pigs. Duroc boars held a similar advantage over Hampshire boars with the difference in litter size being significant $(P<10)$ at 21 and 42 days and the difference in litter weight was significant at 42 days due to a nonsignificant improvement in survival rate of the Duroc sired pigs. No significant breed of sire effects were found for average pig weight at any age. Contrary to results reported by Reddy et al. (1958) and O'Ferrall et al. (1968), these data suggest breed of service sire does affect litter size and preweaning pig livability.

Comparisons among Straightbreds. Straightbred Yorkshire litters were larger $(\mathrm{P}<.05)$ at all ages than straightbred Duroc or Hampshire litters and due to a higher pig survival rate $(P<.05)$ they averaged over two pigs more than Duroc and Hampshire litters at 42 days. Straightbred Yorkshire litters were also the heaviest straightbred litters at 21 and 42 days $(\mathrm{P}<.01)$. Although Yorkshire pigs were the lighest at birth $(\mathrm{P}<.01)$, they were as heavy as Duroc or Hampshire pigs by 21 days. Duroc litters were heavier at birth $(\mathrm{P}<.10)$ than Hampshire litters. However, Hampshire pigs were heavier $(<.05)$ than Duroc pigs at 21 days. No differences among the straightbreds were significant for average pig weight at $\mathbf{4 2}$ days.

Heterosis Estimates. In general, heterosis estimates for number of pigs per litter were larger at 21 and 42 days than at birth. Few estimates of heterosis for average pig weight per litter were significant. However, at all ages, nearly all crossbred pigs averaged heavier than the average of the purebreds involved in the cross, even though the crossbred pigs were from 


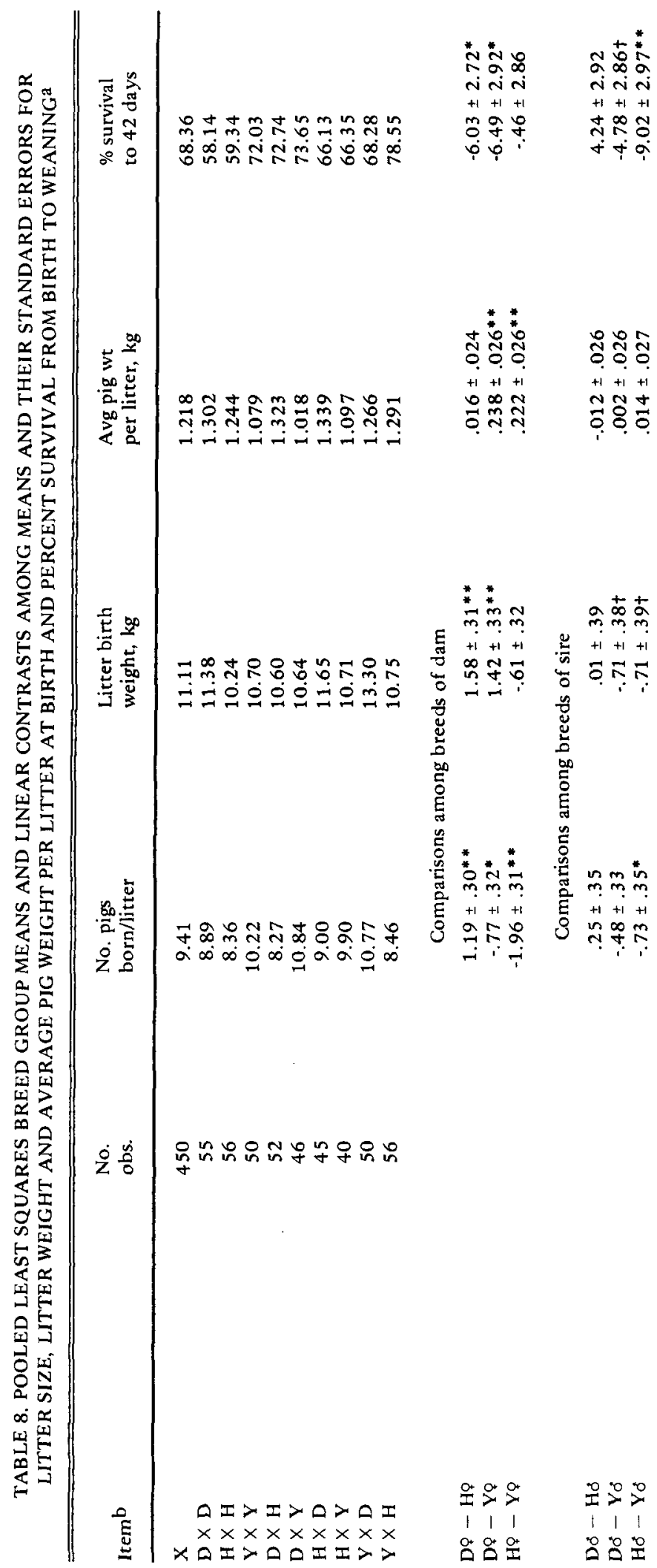




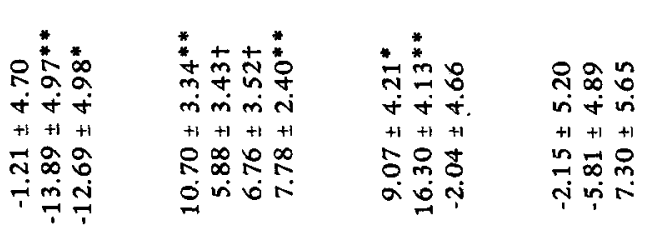

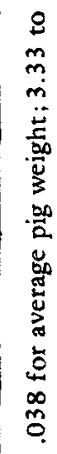

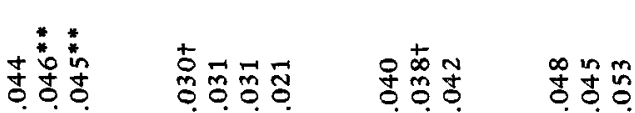

$+i+i+i+i+i \quad+i+i+i+i+i$

กิ่
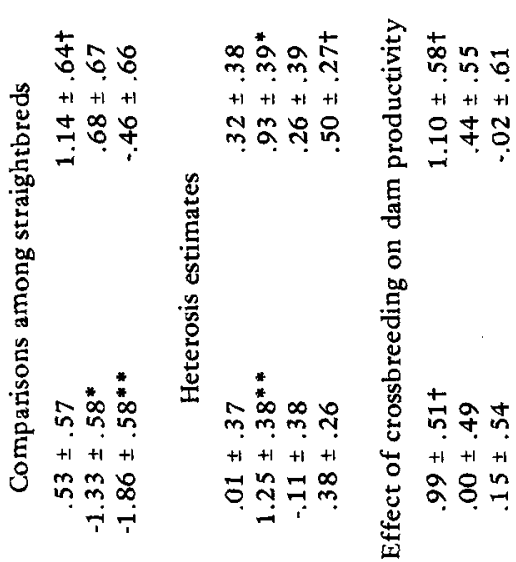

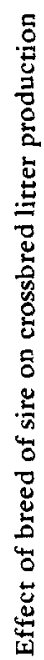

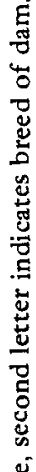

응ำ

$+1+1+1$ in

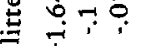

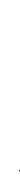

त̣̂ in

Q

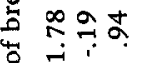




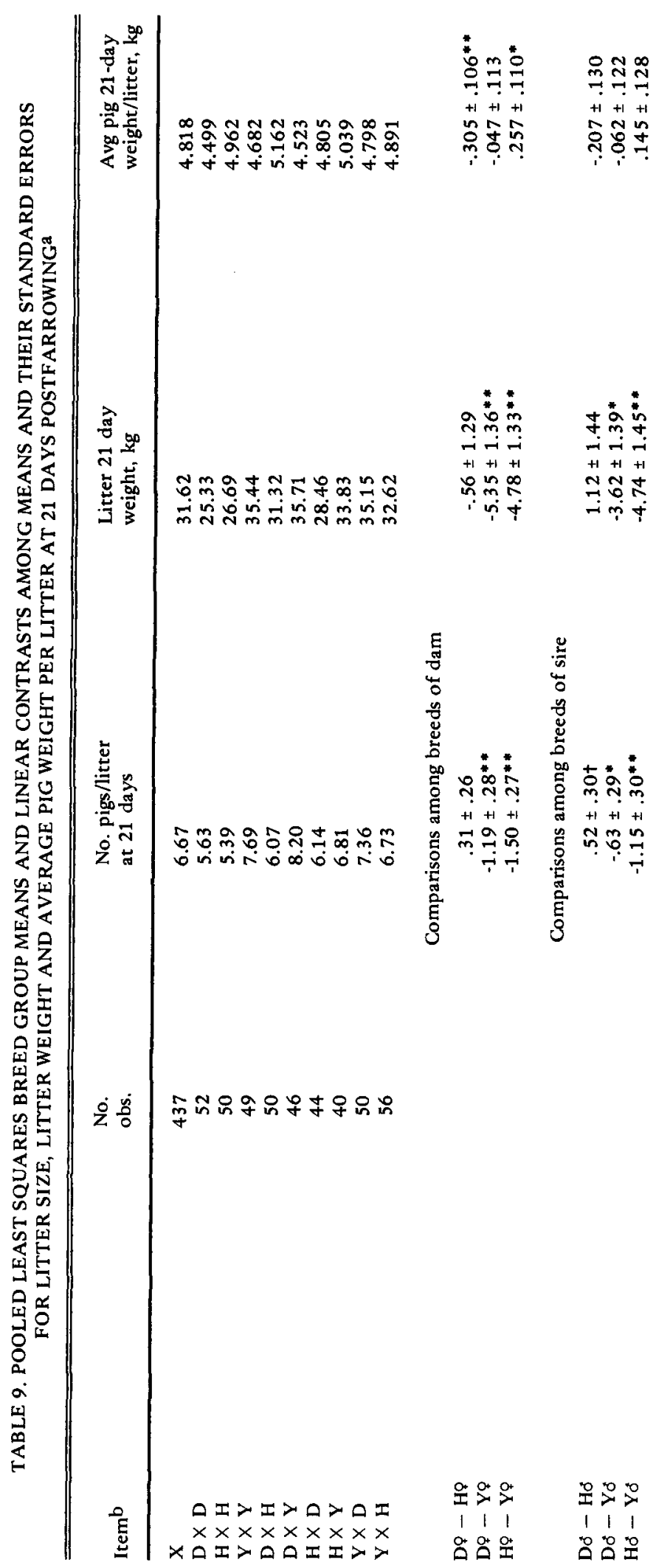


ำกำ

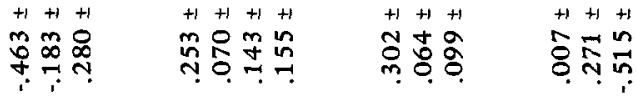

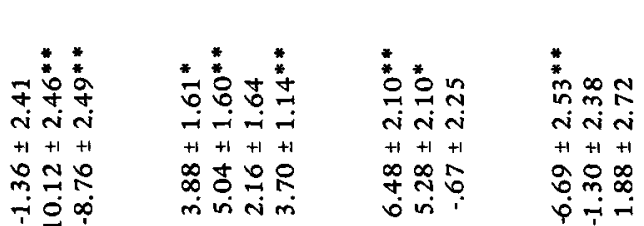

爱

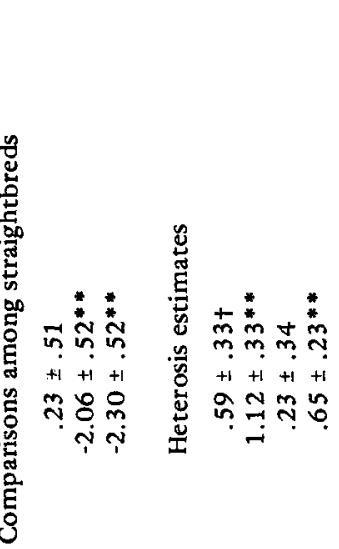

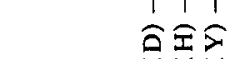

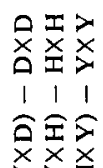

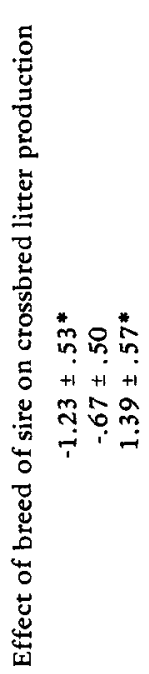

$\underset{x}{x} \times>x$

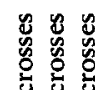

$x \times x$

l 1 1

$00 \frac{7}{x}$

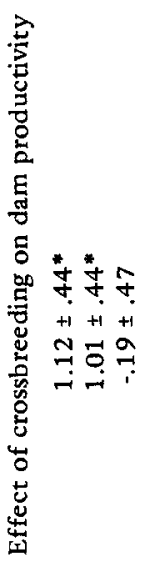

ํㅡㅁㅗㅗ

エン㐅

$+++$

$\times \frac{1}{x}$

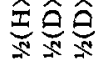




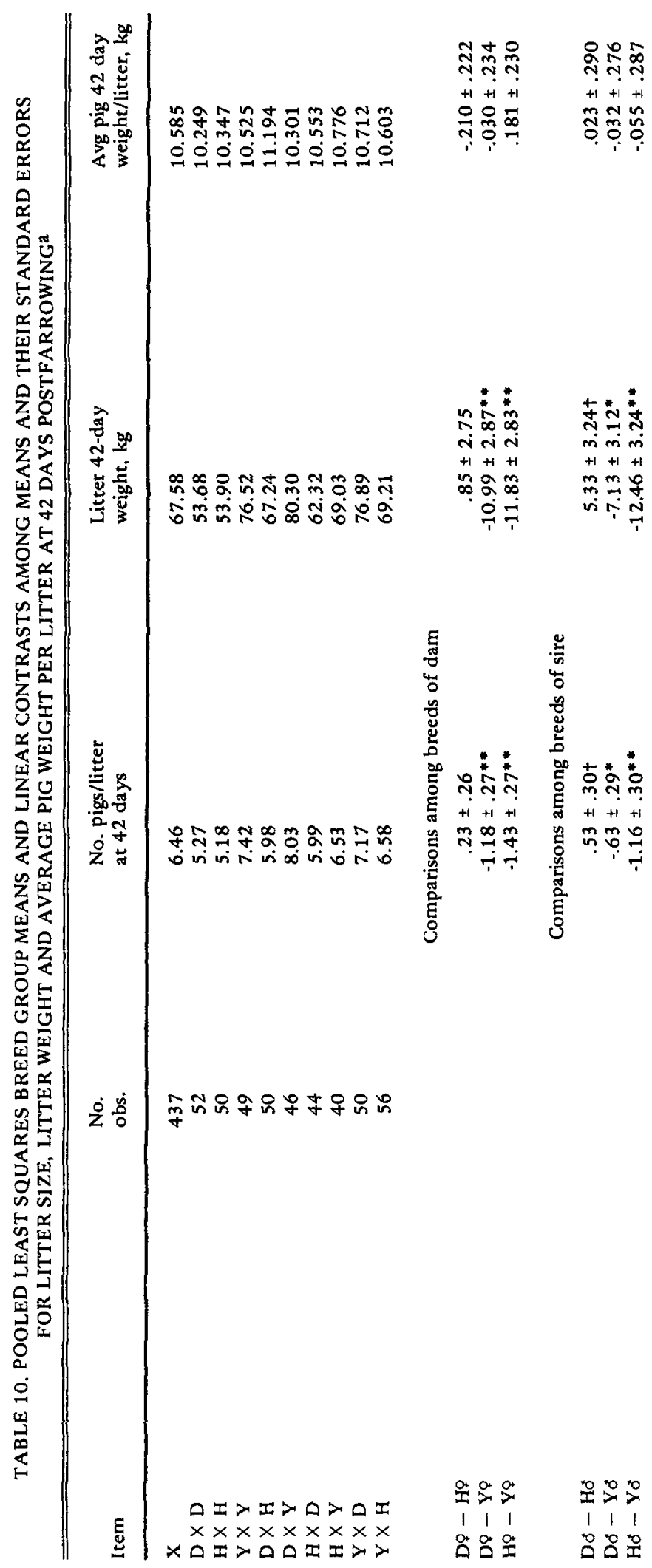




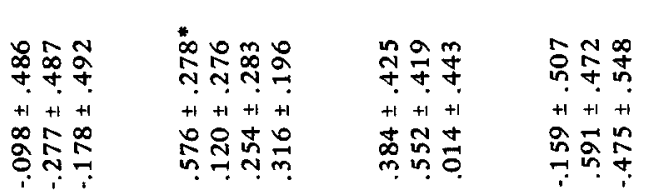

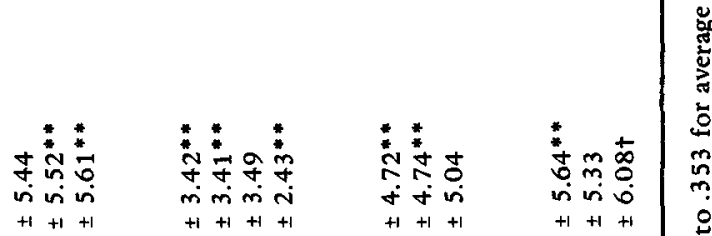

సี艹

กิ่
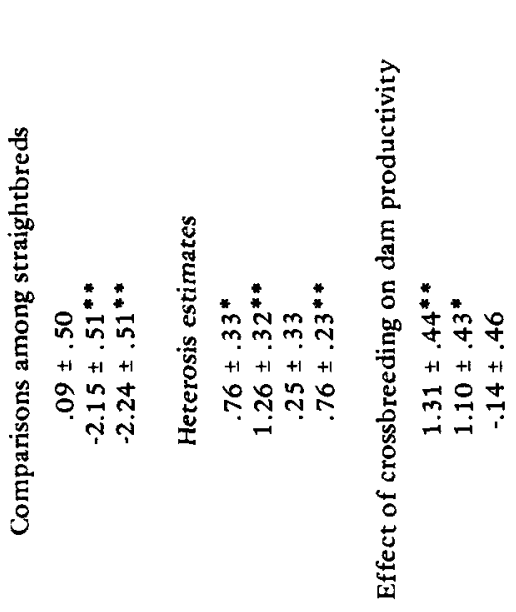

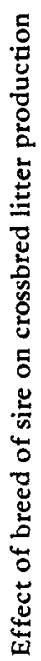

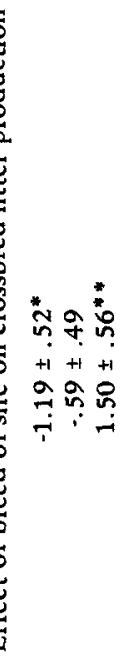

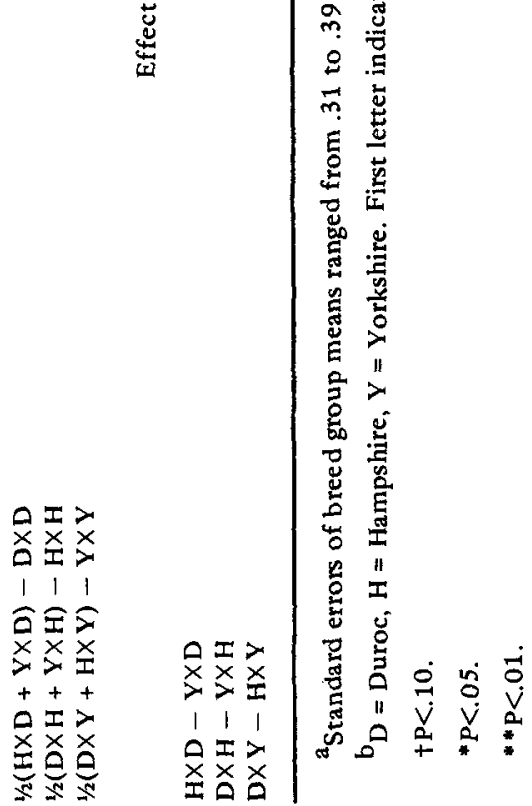

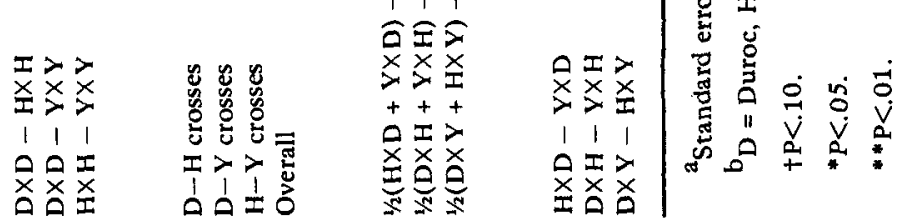


larger litters. Because of the increased number of pigs in crossbred litters and the somewhat heavier average pig weights for crossbred pigs, there were several significant heterosis estimates for litter weight at 21 and 42 days. Consequently, overall crossbred litters averaged $.50 \pm$ $.27 \mathrm{~kg}, 3.70 \pm 1.14 \mathrm{~kg}$ and $9.47 \pm 2.43 \mathrm{~kg}$ heavier than purebred litters at 0,21 and 42 days, respectively.

Nearly all significant estimates of heterosis were observed in Duroc-Hampshire and DurocYorkshire crosses. Heterosis estimates for Hampshire-Yorkshire crosses were in the same direction as for the other crosses but only the estimate of $6.76 \%$ for survival rate was significant $(P<.10)$.

These results are in general agreement with most research which has found that crossbred pigs have a higher survival rate and crossbred litters are consequently heavier and larger at weaning than purebred litters (Winters et al., 1935; Craft, 1953; England and Winters, 1953; Whatley et al., 1954; Smith and McLaren, 1967). Other workers have reported crossbred pigs to be heavier than purebred pigs at birth and weaning (Winters et al., 1935; Lush et al., 1939; Robison, 1948; England and Winters, 1953; Cunningham, 1967). In this study crossbred pigs were $.014 \pm .021 \mathrm{~kg}, .155 \pm .094 \mathrm{~kg}$ and $.316 \pm .196 \mathrm{~kg}$ heavier than purebreds at 0 , 21 and 42 days, respectively.

Average Effect of Crossbreeding on Dam Productivity. Duroc and Hampshire dams responded favorably to crossbreeding but Yorkshire females showed no significant average response to crossbreeding. Duroc dams had significantly larger and heavier litters at all ages when producing crossbred litters than when producing purebred litters. Crossbred and purebred litters from Hampshire females were of equal size and weight at birth but by 42 days the crossbred litters were significantly larger and heavier $(P<.05)$. Crossbred litters from Duroc and Hampshire dams had a $9.07 \pm 4.21$ and $16.30 \pm 4.13 \%$ higher survival rate than purebred litters from these dam breeds. Average pig weight showed little response to crossbreeding and only the estimate for birth weight of pigs from Hampshire dams was significant $(\mathbf{P}<10)$. Yorkshire dams produced crossbred and purebred litters of essentially equal size, weight and survival rate.

Effect of Breed of Sire on Crossbred Litter Production. Within Duroc dams, Yorkshire sired litters were larger and heavier than Hamp- shire sired litters at all ages $(P<.05)$. Within Hampshire dams there was no significant difference between litters sired by Duroc or Yorkshire boars although all averages for litter size, litter weight and survival rate favored the Yorkshire boar. Litters were larger at all ages for Yorkshire females when mated to Duroc males than when mated to Hampshire males. The difference was significant at 21 and 42 days. Although Yorkshire females did not show any large average response to crossbreeding, they did have larger litters at all ages when mated to Duroc boars than when mated pure. Hampshire boars actually decreased the reproductive performance of Yorkshire dams compared to when the Yorkshires were mated pure. This suggests that the response to crossbreeding exhibited by gilts of a specific breed depends on the breed of boar to which they are mated. This also explains the lack of significance for the heterosis estimate for Hampshire-Yorkshire crosses.

These data indicate that of the three breeds evaluated, Yorkshires are the most productive in terms of litter size and weight but Yorkshires also have the highest reproductive failure rate. Definite breed of sire effects were seen on litter size with Yorkshire boars producing the largest litters, and Hampshires the smallest. Heterosis can be expected for litter size and weight at 42 days and for pig survival rate. The three breeds of dam seemed to respond differently to crossbreeding. This response was also dependent on the breed of boar used in the production of the crossbred litter.

\section{LITERATURE CITED}

Alschwede, W. T. and O. W. Robison. 1971. Prenatal and postnatal influences on growth and backfat in swine. J. Anim. Sci. 32:10.

Conover, W. J. 1971. Practical nonparametric statistics. John Wiley and Sons Inc., New York.

Craft, W. A. 1953. Results of swine breeding research. U.S.D.A. Cir. No. 916.

Cunningham, P. J. 1967. Crossbreeding effects on preweaning and postweaning performance in swine. M.S. Thesis. Oklahoma State University.

England, D. C. and L. M. Winters. 1953. The effects of genetic diversity and performance of inbred lines per se on hybrid vigor in swine. J. Anim. Sci. $12: 836$.

Harvey, W. R. 1960. Least squares analyses of data with unequal subclass numbers. U.S.D.A. Pub. A.R.S. 20-8.

Harvey, W. R. 1972. General Outline of Computing Procedures for Six Types of Mixed Models. (Mirneo.) 
Johnson, R. K., I. T. Omtvedt and L. E. Walters. 1973. Evaluation of purebreds and two-breed crosses in swine: Feedlot performance and carcass merit. J. Anim.Sci. 37:18.

Johnson, R. K. and I. T. Omtvedt. 1973. Evaluation of purebreds and two breed crosses in swine: Reproductive performance. J. Anim. Sci. 37:1279.

Lush, J. L., P. S. Shearer and C. C. Culbertson. 1939. Crossbreeding hogs for pork production. Iowa Agr. Exp. Sta. Bull. 380.

O' Ferrall, G. J. More, H. O. Hetzer and J. A. Gaines. 1968. Heterosis in preweaning traits of swine. J. Anim. Sci. 27:17.

Reddy, V. B., J. F. Lasley and D. T. Mayer. 1958.
Genetic aspects of reproduction in swine. Mo. Agr. Exp. Sta. Res. Bull. 666.

Robison, W. L. 1948. Crossbreeding for the production of market hogs. Ohio Agr. Exp. Sta. Res. Bull. 675.

Smith, H. G. and J. B. McLaren. 1967. Performance of breeds and breed crosses of swine. Tenn. Agr. Exp. Sta. Bull. 434

Whatley, J. A., Jr., D. Chambers and D. F. Stephens. 1954. Using hybrid vigour in producing market pigs. Okla. Agr. Exp. Sta. Bull. 415.

Winters, L. M., O. M. Kiser, P. S. Jordon and H. W. Peters. 1935. A six years study of crossbreeding swine. Minn. Agr. Exp. Sta. Bull. 320. 